\title{
A politização do conceito de cultura na teoria institucionalista: Thorstein Veblen e os antropólogos de sua época
}

The politicization of the concept of culture in institutionalist theory: Thorstein Veblen and the anthropologists of his time

Livio Sergio Dias Claudino (1)

(1) Universidade Federal do Pará

\section{Resumo}

$O$ conceito de cultura foi fundamental para o desenvolvimento das ciências sociais e humanas nos séculos XIX e XX. Também está na raiz da escola de pensamento econômico conhecida como Institucionalismo Americano, que teve como precursor Thorstein Veblen (1857-1929). Por meio da leitura de textos clássicos e revisão de literatura, o objetivo deste texto é apresentar o "pensamento antropológico" contemporâneo a Veblen, principalmente em torno do conceito de cultura e do método em Antropologia nos seus primórdios, e discutir as relações interdisciplinares que dão origem à escola de pensamento institucionalista, explicando a retomada da abordagem vebleniana nos últimos anos, especialmente nos estudos sobre consumo. Como principais resultados, destaca-se que Veblen valeu-se de instrumentos investigativos similares, estabelecendo diálogo com os escritos dos etnólogos e influenciando outros, tendo encaminhado o entendimento sobre cultura, principalmente por meio da crítica à "alta cultura", os quais marcaram a noção de cultura na história do Institucionalismo Americano.

\section{Palavras-chave}

antropologia econômica, institucionalimo, culturalismo.

Códigos JEL B15, B52, B25. 


\section{Introdução}

Nas últimas décadas a obra de Thorstein Veblen (1857-1929) tem aparecido com frequência nas discussões acadêmicas de diversos campos disciplinares, seja para oxigenar as reflexões acerca do papel das instituições no desenvolvimento econômico, seja como ponto de partida para tratar do consumo, da propaganda, das questões ambientais ou ainda para fundamentar uma renovada crítica ao mainstream econômico do pós-2008. ${ }^{1}$ Embora sua mais forte influência seja no escopo da Economia, sendo ele o precursor da corrente Institucionalista, também é muito reconhecido na Sociologia, especialmente na Sociologia Econômica (Aron, 1970; Gislain; Steiner, 1995; Gagnon; Faille, 2007; Silva, 2008). Por outro lado, sua posição não parece muito evidente na Antropologia, apesar de alguns assegurarem que ele pode ser considerado o precursor da Antropologia do Consumo (Rocha; Barros, 2006; Rocha; Rocha, 2007), ou pelo menos a referência pioneira incontornável (Duarte, 2010). Não parece que ele mesmo tenha se identificado como antropólogo, e sim etnólogo, ${ }^{2}$ e penso que seria realmente difícil um enquadramento disciplinar visto que sua obra sempre se impõe multidisciplinar (Edgell, 1987; Silva, 2010).

A obra de Veblen foi lida e agenciou autores de peso da Antropologia, como Mary Douglas (1921-2007)³ e Marshal Sahlins (1930-)4. Também sua obra foi muito influenciada pelos clássicos da Antropologia apresentados neste ensaio, conforme aponta Tilman (1992). Pode-se mesmo dizer que

1 Algumas atividades recentes indicam a potência da obra de Veblen para questões contemporâneas: por exemplo, a criação de uma Associação e de um Instituto Veblen na França na última década (http://www.veblen-institute.org/?lang=fr); o dossiê na revista francesa Revue Interventions économiques (Gagnon; Faille, Org., 2007). Os eventos dedicados ao autor, como a Journée d'Études - Autour de Thorstein Veblen: sociologie économique et critique sociale, realizada em março de 2015 em Paris (Universidade de Nanterre) e ainda o colóquio sobre Veblen realizado em Beirute no mês de junho 2015 (http://thorstein.veblen.free.fr/).

2 No prefácio do livro Teoria da classe ociosa (1899), Veblen deixa claro que realizou pesquisa etnológica e observação do cotidiano (Veblen, 1965).

3 Conferir em Douglas e Isherwood (2008 [1979]).

4 Por exemplo, Sahlins refere-se à Veblen para discutir a contribuição da Antropologia evolucionária no estudo das relações entre os homens e as máquinas (tecnologia) (Sahlins, 1972). Em outro texto, utiliza os conceitos veblenianos de ceremony e workmanship para elaborar sua análise funcional das distinções sociais, utilizando um estudo sobre vestimentas (Sahlins, 1991). Ainda em Evolution and culture, Sahlins e Service comentam que os jovens antropólogos culturalistas, americanos e britânicos, começavam a incorporar muitas fontes teóricas, incluindo Veblen, o que, para ele renovaria o evolucionismo (Sahlins; Service, 1960). Uma discussão resumida das influências de Veblen na obra de Sahlins pode ser encontrada em Knoedler; Prasch; Champlin (2007). 
Veblen antecipava o debate que ocorreu entre os anos 1930-1970, envolvendo substantivistas e formalistas, ${ }^{5}$ que se não representou a origem do campo que hoje conhecemos como Antropologia Econômica, integrou o período de sua consolidação. $O$ agenciamento desses debates com a obra de Veblen não é de forma alguma um fato corriqueiro. No entanto, à parte disso, a consulta a textos básicos de história da Antropologia, manuais, dicionários e também alguns currículos de cursos dessa disciplina ${ }^{6}$ evidencia a ausência ou presença periférica dos estudos de Veblen ${ }^{7}$.

O presente artigo se propõe a discutir a influência de antropólogos evolucionistas para o pensamento de Veblen, destacando pontos de aproximação e distanciamentos, bem como sua repercussão para estudos contemporâneos, especialmente na área de Antropologia Econômica e Antropologia do Consumo, fomentando o debate na literatura em torno da multidisciplinaridade inerente à Economia Institucional. Serão apresentados elementos basilares do "pensamento antropológico" contemporâneo a Veblen, apontando os objetos de estudos, quais os métodos utilizados e os temas abordados pelos que figuraram como precursores da disciplina, fazendo o mesmo com a obra de Veblen. Serão três etapas: a) a formação da disciplina, com ênfase nos autores e debates que se desenvolveram na

5 Para uma discussão mais detalhada desse debate, pode-se consultar o texto de Nuno Machado (2012).

6 Por exemplo, no seminário Anthropologie Economique (2015), oferecido na École de Hautes Études en Sciences Sociales (Paris-França), Veblen não aparece (<http://www.ehess.fr/fr/ enseignement/enseignements/2014/ue/126/>). Já na disciplina Antropologia Econômica/Antropologia do Dinheiro e do Consumo (2013), na de Antropologia do Dinheiro e do Consumo e na de Antropologia Econômica (2015), ministradas pelo programa de Pós-Graduação em Antropologia Social da Universidade Federal do Rio Grande do Sul (UFRGS), a obra do autor consta no cronograma (<http://www.ufrgs.br/ppgas/portal/index.php/pt/disciplinas/do-semestre $>$ ). Em relação aos dicionários e manuais de antropologia, segue uma pequena listagem, separados por idioma, indicando os que não incluem citações a Veblen: em francês, o Dictionnaire de l'ethnologie et de l'anthropologie, de Pierre Bonte e Michel Izard (Bonte; Izard, 1991); o Dictionnaire des anthropologistes do professor Paul Émile Duroux (Duroux, 1975); em inglês, o manual dos professores de universidades norte-americanas Readings for a history of Anthropological Theory (Erickson; Murphy, 2001) e o livro Classic Anthropology do professor da Washington University John William Bennett (Bennett, 1998); em italiano, o Dizionario di antropologia: etnologia, antropologia culturale, antropologia sociale (Fabietti; Remotti, 2003). Fazem citações a Veblen: ambos de universidades estadunidenses: The dictionary of anthropology, do professor de Antropologia da Boston University que referencia não como um verbete, da maneira que faz aos demais pesquisadores, mas para contextualizar os verbetes "capitalism" e "conspicuous consumption" (Barfield, 1997), e o Concise dictionary of social and cultural anthropology do antropólogo Mike Morris (Morris, 2012), que cita Veblen no verbete "conspicuous consumption".

7 Murillo Cruz (2014) acredita que, em geral, qualquer antropólogo ou sociólogo conhece, mas não possui informações mais completas sobre a obra e sobre o esquema de pensamento de Veblen. 
Antropologia contemporânea a Veblen; b) os elementos biográficos de Veblen, o foco dos estudos, a metodologia e o tratamento dado às discussões que ocorriam entre os antropólogos de sua época; c) e, por fim, algumas possibilidades de investigações que podem enriquecer as interfaces entre as disciplinas da Economia e da Antropologia a partir da obra de Veblen.

\section{A Antropologia evolucionista}

A publicação do livro A origem das espécies de Charles Darwin, em 1859, influenciou profundamente o pensamento social. Os antropólogos da emergente disciplina investiram na busca pelas analogias biológicas a fim de encontrar as sequências evolutivas que permitissem reconstituir a história da humanidade e o lugar das instituições. A principal preocupação era enquadrar os povos e as instituições sociais na evolução e especificar a origem dessas instituições buscando, nesse enquadramento, explicar as diferenças entre as sociedades (Boas, 2004 [1932]; Pelto, 1967; Laraia, 1999 [1986]; Deliège, 2013). ${ }^{8}$ Ancorada na revolução darwiniana e em busca desses objetivos "científicos" se consolidava a pulsante disciplina. Tendo por fio condutor a ideia de progresso, as sociedades passaram a ser classificadas numa escala que ia da selvageria à civilização, passando pela barbárie. As instituições, como a família nuclear, o cristianismo, a monogamia, a propriedade privada e a organização política parlamentar, serviam como parâmetros para distinguir os grupos considerados superiores dos inferiores.

Olhar para as demais sociedades e suas instituições era como uma volta paleológica ao passado, e a noção de "sobrevivências" tornou-se uma chave metodológica para compreender as distintas etapas e as formas pelas quais as sociedades "primitivas" superavam essa condição (Tylor, 2005 [1871]; Castro, 2005). Os primeiros evolucionistas consideravam que as "sobrevivências" eram instituições, costumes ou ideias típicas de um período que, por meio dos hábitos, conseguiam sobreviver mesmo em sociedades civilizadas. Assim, para cada sobrevivência atribuía-se uma explicação: os sistemas de parentesco não patriarcais eram utilizados para argumentar o

8 Utilizarei os colchetes para indicar o ano de publicação da primeira edição na língua original do texto. Em alguns casos repetirei constantemente, pois é importante fixar o momento em que foram escritos os textos, em outros, apenas o farei na primeira vez que aparecer no texto. 
passado matrilinear; os usos comunais da terra indicavam estágios anteriores à propriedade privada; os rituais de matrimônios que incluíam alguma forma de luta eram utilizados para provar que os casamentos funcionavam por raptos etc. (Deliège, 2013). O peculiar é que as "sobrevivências" sempre pareciam se esconder nas massas "embrutecidas".

Dessa forma, os supostos testemunhos do passado da humanidade permitiam uma tipologia das culturas e sociedades e indicavam a marcha inevitável de todos os grupos rumo à civilização. $O$ objetivo não era entender cada sociedade em particular, mas a totalidade da cultura humana, utilizando principalmente o método comparativo (Erickson; Murphy, 2001), em busca das semelhanças mais do que das diferenças (Deliège, 2013). Jean Duvignaud (1973) pondera que, mesmo com "boas intenções", os evolucionistas sufocaram a originalidade dos grupos considerados como "selvagens" que constituíam sociedades "simples" - afirmação que thes permitia assegurar que complexas e desenvolvidas eram as suas próprias sociedades. Os expoentes da corrente evolucionista que se destacam como fundadores da disciplina serão apresentados nas páginas seguintes: Lewis Morgan (1818-1881), Edward Tylor (1832-1917) e James Frazer (18541941). Cada um deles, ao seu modo e interesses, pautou os principais direcionamentos da Antropologia da virada do século XIX para o XX.

\subsection{Morgan e os sistemas de parentescos}

Do lado norte-americano, o advogado, comerciante e político Lewis Henry Morgan (1818-1881) é apontado como o precursor da disciplina. Em seus estudos junto aos iroqueses, a partir de uma atenção particular aos casamentos e às relações de parentesco e consanguinidade, o antropólogo observou que tanto as denominações parentais (mães, tios, tias, etc.) quanto os sistemas matrimoniais não correspondiam diretamente com as classificações convencionais modernas, mas coincidiam com os de muitas outras tribos no mundo. Nas palavras de Duvignaud (1973, p. 64), Morgan percebeu que as nomeações parentais constituíam uma "configuração total, orgânica ou um sistema". Isso provava, para Morgan, que havia uma origem comum na definição parental e que evoluía em uma trajetória li-

9 Aqui encontramos uma diferença com o pensamento de Veblen, conforme veremos no próximo tópico, pois ele direcionava o olhar para os elementos da alta cultura. 
near, ou seja, antes de se tornar a instituição família monogâmica ocidental foi a "confusão terminológica"10 que ainda predominava entre alguns grupos tribais.

antropólogo acreditou ter encontrado a chave para entender as diferenças entre as sociedades, tendo em vista que descendiam de um tronco comum: as distintas fases de evolução cultural. Essa tese permitia situar todos os povos do mundo sem considerar o tempo cronológico ou a localização geográfica, pois o que importava era a condição atual de cada grupo. A partir de uma matriz, todos seriam enquadrados em algum tempo ou lugar na escala evolutiva, tendo por base as instituições e progressos materiais (Morgan, 2005 [1877]; Castro, 2005; Deliège, 2013). Duvignaud (1973, p. 89) acrescenta que a epistemologia fundada por Morgan se baseou tanto no reconhecimento de que as formas de estabelecer leis de organização eram diferentes entre os indígenas e os "civilizados" quanto na descoberta de que foram esses sistemas "arcaicos" que permitiram a passagem ordenada das formas selvagens às civilizadas.

Convencido da unilinearidade ascendente da humanidade e do funcionamento da evolução, Morgan (2005 [1877], p. 21) resumiu: "Pode-se afirmar agora, com base em convincente evidência, que a selvageria precedeu a barbárie em todas as tribos da humanidade, assim como se sabe que a barbárie precedeu a civilização. A história da raça humana é uma só na fonte, na experiência e no progresso." Posteriormente, o estudioso subdividiu esse esquema de evolução (selvageria, barbárie e civilização) em inferior, intermediário e superior, para as duas primeiras etapas. Essa escala permitia captar facilmente os limites, já que todos os povos tinham passado ou se encontravam em algum ponto. Isso explica o sucesso alcançado por L. H. Morgan, pois foi ele quem propôs o modelo de classificação dos estágios das sociedades de forma mais aceitável à época, partindo do estudo das invenções, descobertas e instituições, explicando que o avanço se dava pela acumulação do saber (Rocha, 1991).

Morgan e os demais evolucionistas direcionaram seus esforços a "retraçar a evolução dessas instituições, das formas mais simples para as mais complexas", com a intenção de descobrir as origens e as etapas de evolução (Deliège, 2013, p. 28). As invenções e as instituições humanas,

10 Expressão utilizada por Deliège (2013, p. 27), na qual destaca que, a partir das análises de linhas de descendência, Morgan postulou que o agrupamento consanguíneo foi uma primeira etapa no desenvolvimento da família monogâmica. 
com os artefatos, registravam os sucessivos progressos, sendo necessário investigá-las a fim de compreender as etapas do progresso. Morgan entendia que "as instituições sociais ou civis, em virtude de sua conexão com os perpétuos desejos humanos desenvolveram-se a partir de uns poucos germes primários de pensamento" plantados nas fases da selvageria ou da barbárie (Morgan, 2005 [1877], p. 21). As instituições, assim, incorporavam e preservavam os principais fatos que a posteriori serviam para ilustrar a experiência humana.

Uma dessas instituições que ele se empenhou em compreender foi a propriedade privada, pois essa se destacava, na opinião do antropólogo, entre aquelas que marcaram a passagem da barbárie para a civilização (Morgan, 2005 [1877]; Castro, 2005). Uma de suas maiores contribuições, além do vasto conhecimento sobre as relações de parentesco que influenciou muitos etnógrafos, foi ter demonstrado que as instituições não são estáticas, e sim imersas em dinâmicas de transformações que resultam de longos processos de evolução. Marx e Engels, em A origem da família, da propriedade privada e do Estado (1884), adotaram alguns pressupostos de Morgan e, como relata Robert Deliège (2013, p. 24), foi por esse "acaso da história" que Morgan tornou-se popular e viu sua obra traduzida para muitas línguas a fim de fomentar os debates marxistas.

\subsection{Tylor e as instituições religiosas}

Edward B. Tylor (1832-1917) é considerado para alguns autores o "precursor" da Antropologia moderna na Europa. Ele foi o autor do primeiro tratado de Antropologia Geral (1871) e também o primeiro a lecionar um curso com esse título, em 1896 na Grã-Bretanha (Bonte; Izard, 1991). Tylor marcou a história do pensamento antropológico em sua busca por compreender a origem das religiões, especialmente estudando entre algumas tribos australianas. Para Thomas Barfield (1997, p. 478), foi Tylor quem empregou de forma conceitual o termo "sobrevivências" (doctrine of survivals) para tratar dos elementos arcaicos que seriam transmitidos ao longo do processo de evolução. O evolucionismo de Tylor se destaca justamente por se concentrar mais no tema das religiões do que na cultura material. Bonte e Izard (1991) apontam que enquanto a maioria dos antropólogos evolucionistas se interessou pelos modos de organização social, Tylor pro- 
curou definir o que era a cultura, esquematizando as etapas da evolução por meio da cognição.

Tylor inferia que a religião era um fenômeno universal, presente em todas as sociedades, e que poderia ser definida como a crença em seres espirituais (Deliège, 2013). Tratada como uma instituição, a religião provinha do desejo humano de explicar racionalmente o que acontece durante os sonhos e após a morte. A forma mais antiga era o "animismo", ${ }^{11}$ sendo esse o ponto inicial da experiência religiosa. Apesar de primitivo, Tylor indicava que o animismo não se extinguira e alguns de seus elementos podiam ser encontrados nas religiões "modernas", na forma de "sobrevivência". Em seu entendimento, ao mesmo tempo que a humanidade evoluía, as religiões ficavam mais complexas, sendo que investigar a vida religiosa dos povos "primitivos" evidenciaria a origem rude da humanidade ao mesmo tempo que forneceria elementos para compreender os civilizados, tendo por pressuposto a movimentação em busca de progresso (Tylor, 2005 [1871]).

O que diferenciava as sociedades era o ritmo com que essas alcançavam o progresso. Tylor (2005 [1871], p. 31) acreditava que investigar a cultura em busca de princípios gerais possibilitaria "um tema adequado para o estudo de leis do pensamento e da ação humana", e "um primeiro passo no estudo da civilização era dissecá-la em detalhes e, em seguida, classificá-la em seus grupos apropriados" (Tylor, 2005 [1871], p. 35). Nesse raciocínio, as similaridades entre as sociedades resultavam de causas uniformes que levaram a ações uniformes, em graus variados, predominando o princípio de causa-efeito, como nas Ciências Naturais. Ele defendia que o estudo da vida social deveria ser como um "ramo" da ciência natural, já que leis similares deveriam governar também a humanidade.

Preocupado com a autonomia da disciplina, Tylor propôs a separação entre a História Geral e a Antropologia. A primeira deveria concentrar-se na história dos grupos tribais e a segunda no entendimento dos costumes, da religião, das leis etc., pois assim seria possível avançar na compreensão da evolução das sociedades. Tylor (2005 [1871], p. 37) também advogava que era possível fazer generalizações, deixando de lado as diferenças in-

11 Tylor definiu, em linhas gerais, que o animismo era a "doutrina da alma e de outros seres espirituais" que subentendia que os humanos são "animados" por forças ou seres sobrenaturais que eles devem se conciliar a partir de práticas especificas (Tylor, 2005 [1871], p. 44; Bonte; Izard, 1991). Deliège (2013) indica que a explanação feita por Tylor foi uma das contribuições essenciais à etnologia. 
dividuais, uma vez que o pesquisador poderia lançar um olhar como que "para um exército do alto de uma colina". Por outro lado, mostrava-se preocupado com o coletivismo e o individualismo metodológico, reconhecendo que as diferenças individuais são importantes, mas não completamente determinantes das ações sociais. Para ele, "esses dois métodos de pesquisa [individualismo e coletivismo], se corretamente seguidos, têm de ser absolutamente consistentes" (Tylor, 2005 [1871], p. 38).

Para Tylor (2005 [1871], p. 40) "progresso, degradação, sobrevivências, renascimento e modificação são todos eles aspectos da conexão que liga a complexa rede da civilização". Assim como outros, Tylor valeu-se da ideia de causação regular e de hábitos ou ideias especiais prevalecentes em uma coletividade, em busca de compreender como essas influenciam os comportamentos a partir das características definidas pelo grupo. Frequentemente chamou a atenção para os elementos antigos que continuam a existir nas sociedades civilizadas, permanecendo como provas da condição humana arcaica e do processo evolutivo, que deveriam ser investigados levando à compreensão da própria sociedade.

\subsection{Frazer, os mitos e as religiões}

O outro "precursor", o britânico James George Frazer (1854-1941), foi o primeiro a lecionar em uma cadeira de Antropologia Social da Liverpool University, Reino Unido (1908), tendo direcionado seus esforços coletando dados sobre mitologia, magia e religião (Barfield, 1997; Castro, 2005; Deliège, 2013). No texto de posse da cadeira docente, Frazer definiu que o objetivo/objeto da Antropologia era "comparar as várias raças de homem, traçar suas afinidades e, por meio de uma ampla coleção de fatos, seguir desde os primórdios, até tão longe quanto possível, a evolução do pensamento e das instituições humanas (...). O objetivo é descobrir leis gerais às quais se possa presumir que os fatos particulares se conformam." O antropólogo entendia que as sociedades tribais eram como a infância da humanidade, tornando possível verificar as fases rudimentares. $\bigcirc$ trabalho seria encontrar as formas embrionárias do pensamento e das instituições, primeiro por meio da observação das crenças e costumes, depois pela identificação das sobrevivências que se conservavam "como fósseis entre os povos de cultura mais elevada", pois "o selvagem é um documento huma- 
no, um registro dos esforços do homem para se elevar acima do nível da besta" (Frazer, 2005 [1908], p. 46-47, 54).

Como o seu interesse era pelo entendimento da vida religiosa, Frazer inquietou-se com o fato de que o pensamento supersticioso permanecia arraigado, apesar do desenvolvimento científico. Para ele, as instituições e ideias transmitidas conservavam formas de pensamento dos antepassados que estavam de acordo com os modos de pensamento e ação na sociedade que as produziu, mas se tornavam incongruentes em contextos subsequentes. Era o caso, por exemplo, das escrituras bíblicas, que refletiam uma época e um lugar específico onde foi escrita (Deliège, 2013), mas que ao se tornarem instituições cristalizam-se como explicações permanentes do mundo natural ou sobrenatural. Para exemplificar o descompasso entre a evolução das ideias e das instituições, ele comparou "a superfície da sociedade, com a do mar, [que] está em perpétuo movimento; suas profundezas, como as do oceano, permanecem quase imóveis" (Frazer, 2005 [1908], p. 54).

Leitor de Tylor, Frazer, ao esboçar uma explicação para essas diferenças entre "a superfície e as profundezas" da sociedade, valeu-se em certa ocasião da noção de "sobrevivências". Para Frazer, as sobrevivências existem devido às diferenças individuais de inteligência, habilidades etc., e também entre as raças que coexistem, mas ao longo da evolução "a maioria estúpida segue a minoria sagaz" e, dessa forma ocorre o progresso, pelo fato de os homens de conhecimento impulsionarem as ações da maioria embrutecida (Frazer, 2005 [1908], p. 51). As diferenças de inteligência geravam uma defasagem contínua no conhecimento, pois, quando uma ideia nova finalmente conseguia chegar às camadas mais baixas, já estava caduca na ponta superior da escala, onde muitas outras ideias mais evoluídas já haviam surgido. Essa era uma das formas pelas quais as "sobrevivências" e as superstições persistiam mesmo nas sociedades mais adiantadas, mas nunca ficavam estagnadas para sempre. Era preciso compreender as transformações nessa trajetória unilinear de desenvolvimento.

Apesar das críticas posteriores, Frazer fez uma importante tarefa de chamar a atenção para missões de campo que conseguissem registrar esses "arquivos" indígenas, antes que sucumbissem aos processos de extermínios que se aceleravam (Frazer, 2005 [1908]). Além disso, contribuiu muito para a tradição dos estudos antropológicos de magia e religião, especialmente por meio de seu livro mais importante, O ramo de ouro (1890). Nesse 
livro, por meio do método comparativo Frazer ele demonstra a semelhança entre os costumes e as tradições dos "selvagens" e as do cristianismo (Castro, 2005), apontando que, em todos os casos, se tratava de falsos sistemas de leis que aprisionavam aqueles que acreditavam nas ilusões provocadas (Deliège, 2013). Frazer fora o último antropólogo do período clássico do evolucionismo cultural e sua morte representou o fim dessa época na disciplina (Malinowski, 1942 apud Castro, 2005), mas não o final de suas ideias, já que essas permaneceram agenciando debates antropológicos por muito tempo.

\subsection{Anotações sobre cultura e método}

Podemos dizer que nesse período de estruturação da disciplina, de busca pelas etapas da evolução e do enquadramento de cada sociedade (Deliège, 2013) o conceito de cultura foi fundamental e tornou-se o principal norteador das investigações (Rocha, 1991), tornando possível escapar do impasse de como mensurar os níveis de progresso. ${ }^{12}$ Tylor foi quem propôs uma primeira definição mais sistemática, quando disse que "cultura ou civilização, no sentido etnográfico estrito, é todo esse complexo que inclui conhecimento, crença, arte, leis, moral, costumes e quaisquer outras capacidades e hábitos adquiridos pelo homem enquanto membro da sociedade" (Tylor, 2005 [1871], p.31). Cultura era considerada como sinônimo de civilização e, portanto, era determinada no singular (Castro, 2005), hierarquizada por meio de estágios que podiam ser alcançados, mas não distribuídos entre todos os povos.

Tylor (2005 [1871]) acrescentou que o trabalho do etnógrafo seria como o do naturalista que faz classificações, baseando-se nos utensílios, nos costumes, nos animais domésticos etc., de forma a compor um catálogo de distribuição geográfica dos grupos humanos por similaridades. Como

12 É bom lembrar que a produção e circulação dessas ideias se deram numa época turbulenta nos espaços acadêmicos e no mundo político. A revolução darwiniana se consolidava; algumas colônias conquistavam independência; a abolição do modo de produção escravagista, na maior parte dos países, ainda era muito recente; diversas expedições desde o continente europeu eram realizadas para "conhecer" os povos "primitivos". Nessas grandes investidas colonizadoras muitas populações ameríndias foram exterminadas em nome da ocupação de terras e exploração de recursos, entre outras situações de conflitos que envolviam a questão da dominação assentada nas diferenças étnicas e na ampliação de territórios e populações governáveis. 
não havia ainda o trabalho de campo - que assumiu a feição a partir da incursão realizada por Bronislaw Malinowski (1884-1942) às ilhas Trobriand, entre os anos de 1914 e $1918^{13}$-, a principal fonte de informações provinha dos relatos de viajantes (missionários, militares, comerciantes, naturalistas etc.), e cabia ao pesquisador discernir entre os autênticos e os fantasiosos. Entre os três "fundadores" da Antropologia, Morgan foi o que mais se aproximou da experiência de campo. Duvignaud (1973) pondera que o recenseamento dos iroqueses realizado por Morgan deve ter sido a primeira "enquête anthropologique de terrain". Porém, ele é considerado uma exceção à regra, e predominou entre os evolucionistas a imagem do antropólogo em sua biblioteca ou gabinete, valendo-se de fontes secundárias (Castro, 2005).

Deliège (2013) destaca que o interesse essencialmente histórico dos evolucionistas lançou as bases para a disciplina, colocando questões fundamentais e incitando os alunos a recolherem mais e mais materiais. De uma disciplina muito especulativa, a Antropologia tornou-se cada vez mais baseada no conhecimento empírico. Por outro lado, os equívocos cometidos pelos evolucionistas provocaram forte rechaço de seus pressupostos, levando a disciplina a um encaminhamento bem diverso, abandonando a linearidade, mas deixando sem solução a questão colocada acerca das origens das instituições. Franz Boas é apontado como um dos principais expoentes da corrente que solapou essa primeira fase da disciplina.

\section{O culturalismo americano de Franz Boas}

O rompimento com o etapismo e com o método comparativo de gabinete é, em grande medida, atribuído ao alemão que viveu boa parte de sua vida nos Estados Unidos, Franz Boas (1858-1942). Boas desenvolveu a tese

13 O trabalho marcante de Malinowski foi o clássico Os argonautas do Pacífico Ocidental, publicado em 1922. Nele, o autor apresenta uma festa chamada Kula, na qual ocorriam trocas de braceletes e colares feitos de conchas entre parceiros escolhidos anteriormente. Os objetos eram trocados e circulavam em um pequeno conjunto de aldeias, durante um período que variava de 2 a 10 anos. O ideal é que retornassem aos antigos donos ao final de um circuito de trocas. Malinowski percebeu que o importante não era o valor utilitário ou comercial, mas sua posse pura e simples, que era plena de significados para aqueles grupos. Ao retornar do trabalho de campo, o antropólogo pôde identificar nas joias da Coroa do Império Britânico relações com os objetos que equivaliam àquelas entre o grupo que ele estudara, ou seja, relações não econômicas ou utilitaristas, mas baseadas nos sentimentos ligados ao prazer de possuir tais objetos (Rocha, 1991). 
de que a diversidade cultural só poderia ser entendida considerando-se as especificidades de cada cultura e aceitando que as semelhanças também poderiam ter se originado pelo contato com outros grupos (por meio das guerras, viagens, comércio etc.).

Entendia que para "compreender a história, não é preciso saber apenas como as coisas são, mas como elas vieram a ser assim", instigando que a questão da cultura é essencialmente um problema histórico. Para ele, os métodos indiretos utilizados tornavam fácil identificar a dispersão dos fenômenos, mas diziam pouco a respeito das causas internas, sendo esse um gargalo para a construção do conhecimento antropológico (Boas, 2004 [1920], p. 45). Em um texto publicado em 1896, Boas propôs investigações específicas para compreender as diferenças culturais, por meio de estudos que abrangessem as influências: a) das condições ambientais, b) dos fatores psicológicos e, c) dos efeitos de conexões históricas. Com isso, estava sugerindo que os estudiosos comparassem as histórias das culturas, e não as culturas: era o início de uma corrente que ficou conhecida como particularismo histórico. ${ }^{14}$

Além disso, Boas (2004 [1920], p. 46-47) ressaltou que nos fenômenos sociais, um efeito pode tornar-se também uma causa, resultando em "efeito cumulativo" entre os fenômenos. Assim, para estudar as mudanças era importante considerar as relações entre indivíduos e sociedades, pois "as atividades dos indivíduos são em grande medida influenciadas pelo ambiente social; por sua vez as atividades podem modificar a sociedade, provocando mudanças de forma". Boas (2004 [1932]) continuou a questionar: que sucessões de coisas aconteceram e quais delas provocaram as mudanças percebidas? E, como obter e quais dados buscar para conhecer os fenômenos sociais, agora tão diversos, e não mais pensados em uma trajetória que se supunha conhecer o início e o fim, restando apenas preencher as lacunas?

Até então, no escopo da Antropologia predominava o entendimento de que a humanidade seguia uma trajetória linear de desenvolvimento. A proposição boasiana redirecionou o caminho, de um trabalho que consistia na classificação das etapas, para um processo de compreensão das culturas como particulares e específicas e com sentido plural. Para autores como

14 Para Boas (2004 [1920], p. 38), "a importância do método histórico da Antropologia está na habilidade para descobrir processos que, em casos definidos, levam ao desenvolvimento de certos costumes". 
Everardo Rocha (1991), esse redirecionamento fez ruir as bases com que se construíram a ideia de superioridade, provocando rupturas na arquitetura bastante engenhosa elaborada pelos anteriores, abrindo espaço para novas investigações antropológicas. ${ }^{15}$

De maneira geral, os três primeiros antropólogos representam a fase da Antropologia evolucionista e Boas marcou a virada para o culturalismo, mas todos são considerados precursores da moderna Antropologia. Todos viveram na época em que os "campos disciplinares" estavam delimitando as fronteiras que os distinguissem dos demais grupos, propondo objetos e métodos específicos. A Antropologia tentava se distinguir da Sociologia, da História, da História Natural, da Economia etc., ao mesmo tempo que Thorstein Veblen, embora reverberando suas ideias no campo da Economia, tentava apagar os limites disciplinares de sua própria obra, especialmente no que concerne à Antropologia, Sociologia e História (Cruz, 2014). Esse breve percurso pela história da Antropologia evolucionista, seguida do culturalismo boasiano, servirá de base para a discussão sobre a obra de Veblen e seus distanciamentos e aproximações dos demais etnólogos apresentados, passando pelo seu entendimento sobre cultura e método científico.

\section{0 ataque à "alta cultura" e a abordagem antropoló- gica de Thorstein Veblen}

Thorstein Veblen (1857-1929) foi, segundo Raymond Aron, solitário e à margem do pensamento acadêmico de sua época. Era filho de um agricultor norueguês emigrado e nasceu no estado de Wisconsin, Estados Unidos. Teve a sua obra influenciada pela experiência pessoal de ver o contraste entre os trabalhadores camponeses e a classe dos burgueses; ricos não pelo próprio trabalho, mas por operações, legais ou ilegais que exploravam

15 Apesar de suas enormes contribuições, sendo ele o defensor do relativismo e tendo um espírito livre e questionador, terminou por nunca explicitar de maneira sistemática e sintética o seu pensamento (Deliège, 2013). Ele colocava mais questões do que respostas e, na opinião de Rocha (1991, p. 41-42), "estilhaç[ou] o bolo de ideias superorganizadas como o evolucionismo e, no seu lugar, deixa os estilhaços como possibilidades a serem exploradas (...). Boas não organizou e apresentou (...) uma teoria da cultura que permitisse (...) tomá-la como conteúdo evidente do seu trabalho". Porém, abriu o caminho para as novas frentes de pesquisas da disciplina, fundando o que ficou conhecido como Culturalismo ou Escola Americana. 
utilizando também a manipulação de símbolos (Aron, 1970). Sua obra é caracterizada pelo debate direcionado aos economistas e aos empresários capitalistas de sua época.

Por meio de uma série de artigos, Veblen demonstrou que, diferentemente de outras ciências, a Economia ainda não havia feito a transição pós-darwinismo e, no seio dessa ciência, os preceitos teleológicos ainda subsistiam como determinações metodológicas (Cavalieri, 2015). Geoffrey M. Hodgson (1992) destaca que o importante não era a busca por leis imutáveis da natureza, mas entender os múltiplos processos de causação cumulativa. Veblen é considerado um dos primeiros estudiosos a adotar os princípios da teoria darwiniana para interpretar o surgimento e evolução das instituições humanas, especialmente aquelas que sofrem tensões proporcionadas pelas relações econômicas (Conceição, 2002). Apesar do darwinismo predominante, Hodgson (1998) argumenta que a teoria de Veblen é evolucionária e não evolucionista, pois, refuta a ideia simples de evolução como progresso e os princípios do reducionismo biológico, e desenvolve uma abordagem envolvendo múltiplos níveis biológicos e socioeconômicos que inclui instintos, hábitos, instituições, estruturas, história e propriedades emergentes.

Apesar da ênfase nas instituições econômicas, Veblen não entendia que toda a vida estava subordinada às relações econômicas. Para ele, as instituições econômicas eram "métodos habituais de dar continuação ao modo de vida da comunidade em contato com o ambiente material no qual ela vive" (Veblen, 1965 [1899], p. 182). A vida humana configurava-se como a luta pela sobrevivência, ocorrendo por meio de um processo de adaptação seletiva. Também a evolução da sociedade seria um processo de seleção natural das instituições, entendidas, de maneira ampla, como os hábitos de pensamento e de comportamento que são compartilhados (Veblen, 1965 [1899]; Hodgson, 1992). Por sua vez, a mudança das instituições levaria à seleção dos indivíduos, já que as instituições resultam dos processos seletivos e da adaptação forçada de tipos predominantes e prevalecentes de atitudes e aptidões, em um ambiente que está sempre em transformação.

Veblen via os processos de mudanças como algo infindável, sendo que sempre as instituições estavam defasadas, pois foram produzidas em contextos anteriores, nunca estando em conformidade com a sociedade atual. Assim como os etnólogos comentados (especialmente Tylor), ele procura- 
va compreender como ocorre a mudança gradual no conhecimento, indo do pensamento animista para o prosaico, ${ }^{16}$ e como o ambiente sociocultural e tecnológico condicionam as mudanças nas formas de pensar de uma maneira mais geral (Veblen, 1919; Cavalieri, 2015). Para Veblen, o animismo resulta da curiosidade humana de tentar interpretar os fenômenos biológicos e naturais, guiados pelo que ele chamou de idle curiosity. Porém, o animismo inspirava lendas, mitos e superstições e levavam a explicações da vida que envolviam forças sobrenaturais, atrapalhando o avanço tecnológico e o uso das artes técnicas e mecânicas e, por isso, foi enfático em criticar a legitimação do animismo como forma de explicação dos fenômenos naturais (Hobson, 1991 [1936]).

Enquanto etnólogo, Veblen explorou textos produzidos sobre as sociedades ditas "primitivas" e construiu um sofisticado esquema interpretativo da evolução humana. O esquema era distinto do de Morgan, tanto nas etapas quanto na trajetória, pois Veblen não via uma condução incondicional ao progresso. Assumindo que há divergências entre os autores que esquematizam as fases descritas por Veblen, pode-se considerar que são duas grandes etapas, a "Selvagem pacífica" e a "Predatória" ${ }^{17} \mathrm{O}$ mais importante a ser destacado é que, como bem lembrou Ghiraldelli-Junior, Veblen não via o processo de civilização como progresso. nem como uma superação da agressividade, mas que, ao contrário, a própria passagem da natureza à cultura ou à civilização teria levado ao aparecimento, renovação ou fortalecimento da compulsão à violência (Ghiraldelli-Junior, 1994).

Distintamente dos antropólogos que acabamos de apresentar, Veblen estava mais interessado em demonstrar como se instituiu e como operava nas sociedades modernas ${ }^{18}$ o que ele chamou de classe ociosa. Para ele, a

16 Prosaico refere-se ao prático, comum, trivial, desprovido de nobreza (HOUAISS, 2001). 17 Em nota na primeira página da versão francesa de Teoria da Classe Ociosa (Veblen, 1970), os editores apresentam quatro etapas econômicas no Ocidente: o neolítico, ou estágio selvagem e pacífico; a barbárie ou predatório, marcado pela instituição da propriedade e da superioridade masculina e pelas atividades guerreiras; a época artesanal, que é anterior ao mundo moderno; e a época da mecânica ou das máquinas. Já Murillo Cruz (2014, p. 36-45) elabora um esquema dessas etapas de evolução cultural um pouco mais detalhado, sendo duas grandes divisões: Selvageria Pacífica (The Savage Stage) e Etapa Predatória (The Predatory Stage). Posteriormente, a segunda etapa foi subdividida em duas: o Estágio Bárbaro (The Barbarian Stage) e o Estágio Pecuniário Recente (The Pecuniary Stage ou The Semi-Peaceable Phase of Predation). Por fim, o Estágio Pecuniário Recente é subdividido em: Era do Artesanato (The Handicraft Era) e, Era Mecânica (The Machine Era ou The Modern Industrial System).

18 Frazer (2005 [1908], p. 48) deixou muito claro que a Antropologia não deveria se ocupar dos problemas contemporâneos, ao declarar que: "Desse modo, a esfera da Antropologia Social como eu a entendo ou, pelo menos, como proponho tratá-la, está limitada aos brutos 
classe ociosa surgiu com a instituição da propriedade privada, concomitante ao processo de legitimação da discriminação entre as atividades consideradas dignas e as indignas. Durante o processo de evolução cultural, o não trabalho produtivo passou a ser honrado, um atributo das classes superiores. O ócio e a ostentação da não necessidade de trabalho passaram a se constituir em provas de superioridade. Ócio não queria dizer vagabundagem ou falta de atividades, mas não desempenhar atividades produtivas e exibir consumo conspícuo, que podia ser demonstrado pela posse de serviçais e escravos, participar de atividades ou consumir produtos e serviços com fins de ostentação e até mesmo as ocupações clericais e as atividades esportivas de competição. Todas demonstravam a capacidade de dispêndio de tempo e recursos (VEBLEN, 1965 [1899]).

Veblen tinha uma visão bastante crítica, e também reducionista, daquilo que ele via como alta cultura. Para ele, nos primórdios, a cultura "consistia na aquisição de conhecimento e de desenvoltura no trato de um agente sobrenatural", sendo que esse conhecimento adquirido e de posse dos mestres sacerdotais "era em grande extensão um conhecimento do ritual e do cerimonial; isto é, um conhecimento da maneira mais apropriada, mais efetiva ou mais aceitável de abordagem dos agentes sobrenaturais e de prestação de serviços aos mencionados agentes". Na interpretação de Veblen, o conhecimento de alguns "processos naturais que pudessem servir ao efeito espetacular" e a legitimação do prestígio para com os sacerdotes estavam na fonte do surgimento "da cultura como uma instituição" (...) "e sua diferenciação desse acervo ancestral de ritual mágico e fraude xamanística foi lenta e enfadonha, continuando até hoje incompleta mesmo nos mais adiantados seminários de alta cultura" (Veblen, 1965, p. 328-329).

Veblen entendia que a "cultura" era funcional e utilizada enquanto práticas e discursos que serviam para distinguir os possuidores e aqueles desprovidos de conhecimento específico, que necessitavam de intermediação. A "cultura" tinha gradações úteis aos grupos dominantes e separava classes. Continuando essa argumentação, Veblen (1965) ponderou que o avanço na produção do conhecimento sistematizado promoveu gradualmente a diferenciação entre a cultura mais alta e a mais baixa e, voltando suas maduras daquele complexo crescimento e menos ainda abrange os problemas práticos com os quais nossos modernos estadistas e legisladores são chamados a lidar." 
análises para o sistema educacional, apontou que essa distinção funcional passara a predominar nos espaços educacionais superiores, onde os rituais e cerimonialismos (como vestimentas específicas, matrículas, honrarias etc.) eram mais evidentes e intensos. Era lá que residiam as "sobrevivências" mais arcaicas dessa origem da cultura.

O resultado do processo de valorização dos elementos constitutivos da alta cultura no sistema educacional seria, na visão de Veblen (1965, p. 333), a "preparação da juventude das classes ociosa e sacerdotal (ou de uma classe ociosa incipiente) para o consumo de bens, materiais e imateriais, de acordo com um programa e um método honoríficos, convencionalmente aceitos". O autor resume que "os hábitos mentais que caracterizam a vida da classe [ociosa] giram em torno da relação pessoal de domínio e de conceitos derivativos e emulativos de honra, dignidade, mérito, caráter e coisas semelhantes (...). [no entanto] Tampouco a dignidade esta[va] ligada ao conhecimento de fatos vulgarmente úteis" (Veblen, 1965, p. 345). E a habituação ao consumo ostensivo não ficava apenas na classe ociosa. Veblen percebia a transposição de elementos culturais das classes ociosas nas comunidades pobres, por intermédio de "funções educativas", como parte de um processo de dominação cultural.

Os valores dos grupos dominantes eram apresentados como bom gosto e refinamento nas missões culturais. Essas serviam para "inculcar, por preceitos e exemplo, certas miúdas formalidades referentes às conveniências da classe superior, no tocante às maneiras e aos costumes (...). A propaganda cultural é em grande parte uma inoculação de novos gostos ou, antes, de um novo programa de conveniências, adaptadas ao esquema de vida da classe superior segundo a formulação da classe ociosa no tocante aos princípios de status e decência pecuniária" (Veblen, 1965, p. 311-312). Veblen considerava também que esse programa cultural imposto dificilmente poderia ser mais conveniente do que aqueles que as populações viviam ou estavam forjando sob a pressão da vida industrial que avançava. $\mathrm{O}$ autor criticou também que a demonstração de solicitude carregava cada vez mais elementos meritórios, e era feita sem se preocupar em conhecer as condições materiais e hábitos daqueles populares que recebiam medidas para melhorar-lhes o "progresso cultural". Essa era uma forma de acelerar a aceitação dos hábitos culturais das classes ociosas ao esquema diário entre os grupos considerados inferiores. 
Esse ataque de Veblen à alta cultura foi incisivo e a ofensiva não passou ilesa. Entre os muitos críticos a Veblen, ${ }^{19}$ destaca-se o filósofo Theodor Adorno (1903-1969), um dos principais membros fundadores, com Max Horkheimer (1895-1973), da escola de neomarxistas de Frankfurt. Em um texto chamado "O ataque de Veblen à cultura" (publicado no livro Crítica de la cultura y sociedade I, em 1977), Adorno (2008) tece comentários que colocam em xeque a coerência da teoria e até mesmo a sanidade mental de Veblen. ${ }^{20}$ Por outro lado, explana, de forma perspicaz, características da teoria de Veblen que certamente favoreceram o olhar atento ao excêntrico institucionalista.

Adorno (2008 [1977], p. 63) aponta que, "en innumerables passajes es claríssima la intención de denunciar como barbárie a la modernidade cuando plantea con vigor la pretensinón de cultura. Precisamente los rasgos en que la modernidad se revela digna del ser humano porque se ha escapado de la utilidad desnuda son para Veblen vistígios de épocas muy antiguas." Segundo o crítico, essa emancipação do "reino das utilidades" são, para Veblen, o índice de inutilidade provocado pelo fato de as instituições culturais e disposições antropológicas não mudarem ao mesmo tempo e de acordo com os modos econômicos de produção, onde a cultura se volta contra a "utilidade". Apesar das críticas, o frankfurtiano reconhece que Veblen teve sensibilidade capaz de perceber e de constituir uma teoria do consumo pioneiramente, pois conseguiu captar a falsa individualidade das coisas muito antes que os procedimentos técnicos efetivamente o conseguissem.

Essas críticas nos levam a outra direção, passado o tempo desde as obras dos dois filósofos, e de acordo com a proposta deste artigo. A mais importante diz respeito à possibilidade de entender que Veblen, com o seu

19 Devido aos objetivos deste ensaio, não avançaremos nas críticas. Para maiores aprofundamentos sobre as críticas, consultar Hodgson (1992), Stanfield (1999) e Tilman (1992).

20 Adorno (2008 [1977]) acusa Veblen de hipostasiar (transformar algo em substância), por indicar uma espécie de domínio total onde toda a cultura da humanidade se converte em uma caricatura do horror. O crítico afirma ainda que Veblen tinha fascínio pela miséria (desdicha) e, por isso, atacou a cultura. Chama-o de misantropo, tendo por consequência enxergar rastros de sangue das injustiças até mesmo nas imagens de felicidade; como se a possibilidade de esperança estivesse na condição primitiva do homem, quando eram mais pacíficos. Adorno chega mesmo a considerar que Veblen é vítima de spleen, condição caracterizada por uma melancolia extrema, tendente à autodestruição, onde a acusação é uma forma de defesa. $O$ filosofo de Frankfurt destaca que, diante de Veblen, os ornamentos se tornam ameaças, pois são velhos modelos de repressão; as decorações das fundações são vestígios de épocas passadas ou traços de regressão de quem não produz e não trabalha, desmentindo a mentalidade favorável do progresso. 
pessimismo e a crítica da sua própria sociedade, ou melhor, dos homens e valores considerados como "de sucesso", ${ }^{21}$ antecipava a crítica cultural que fizera o próprio Adorno. Veblen desconfiava daquilo que era tido como mais "honrado e meritoso" e de "bom gosto", atacando, como afirmou Adorno, os próprios motivos/símbolos máximos da classificação das sociedades em superiores/inferiores: a cultura.

Veblen convidada a olhar para os motivos de maior orgulho, e não para aquilo que parecia indigno. Ao desacreditar no progresso inevitável rumo à civilização, Veblen rompia, de certa forma, com a tradicional linearidade ascendente, apesar de fazer o mesmo movimento dos demais de tentar apagar as diferenças. Ele buscava as "sobrevivências" onde os demais não davam importância, e colocava as relações de poder no centro das análises e, mais precisamente, politizava o conceito de cultura. Essa parece ter sido a forma iconoclasta peculiar a Veblen de identificar as formas de dominação e também a possibilidade de superação da própria condição humana que tanto lhe preocupava.

Veblen, com sua crítica direcionada, via que as ciências econômicas não poderiam se constituir autonomamente. James R. Stanfield (1999) argumenta o esforço de Veblen para demonstrar uma concepção diferente da própria economia, concebendo-a como o sistema de atividades relacionadas que envolve um conjunto de conhecimentos e de competências, equipamentos físicos e também uma complexa rede de relações reforçadas por costumes, rituais, sentimentos, dogmas e relações de poder. Veblen reclamava, com sua abordagem, que as preferências das pessoas não estavam dadas e deveriam ser explicadas. Entendia que os desejos, as instituições e a tecnologias não mudam de forma aleatória, mas respondem às influências que são próprias aos sistemas sociais. Dessa forma, o precursor do Institucionalismo Americano colocava as relações de poder e a formação dos hábitos como elementos centrais para entender a economia e a mudança social.

Mas Veblen sabia que seus métodos de pesquisa não estavam totalmente enquadrados no escopo da pesquisa econômica de sua época. Tanto é que justifica no prefacio do livro TCO, explicando que seu estudo se "processa com base na teoria econômica ou de generalização etnológica class endows it with a prescriptive power to impose its values on the whole of society via the process of emulation". 
(...), parte em virtude (...) dos dados empregados para ilustrar ou acentuar o argumento foram de preferência tirados da vida diária, mediante observação direta ou notoriedade patente, antes que de fontes secundárias mais recônditas" (Veblen, 1965, p. 10). E realmente, sua obra (TCO) deixa claro que ele utiliza o método comparativo, por meio de registros etnológicos de outros autores e de observação direta de sua própria sociedade.

Stanfield (1999) destaca que, de maneira geral, na escola de pensamento fundada por Veblen - Original Institutional Economics (OIE) - não há ênfase em modelos econométricos. Esse autor resume que a abordagem vebleniana baseia-se nos métodos comparativos dos antropólogos de sua época para coletar e analisar as informações, valendo-se também de observação participante para a composição de registros etnográficos, priorizando a interpretação das ações, diferentemente da análise econômica tradicional que isola e homogeneíza os comportamentos.

Stanfield completa:

OIE relies on the comparative method developed by anthropologists to collect information (...). [And] tends to rely more upon examination of qualitative empirical information of a historical and cultural nature and upon descriptive rather than inferential use of quantitative information (...). The comparative method relies upon the execution of case studies or field studies by which investigators carefully compile information about the activities of a human group. Field studies are specifications of the activities, the rules, and the applicable understandings or cultural underpinnings that comprise human behavior unfolding in an institutional context. The summation of these field studies is the ethnographic record, the codified assemblage of what we know of human behavior in place and time. Interpretation of this ethnographic record is necessary (...). Historical situations or cases are recounted and compared in an effort to discern a pattern or general element. This interpretive effort is quite different from the conventional scientific procedure of isolation and reduction. (...) The method of participant observation is also a key element in the makeup of OIE (Stanfield, 1999, p. 236-237).

Embora muito respeitado, houve certa rejeição aos escritos de Veblen em sua época. Tomando por base os comentários de revisor anônimo, é possível supor que a rejeição deriva do fato de ele ser um eminente crítico dos pressupostos marginalistas que, segundo alguns autores, tendia a ser a corrente hegemônica na academia americana no início do século XX (ROSS, 1991). Contudo, o caráter dessa hegemonia é alvo de grande discussão, pois segundo uma linha importante do debate sobre história do pensamento econômico, naquele período reinava entre os economistas norte-americanos a conformação de um espaço epistêmico plural, com aceitação e reconhecimento de diversos métodos, de modo que mesmo as fronteiras entre as escolas e os métodos que as caracterizavam não eram claramente 
definidos (Colander; Landreth, 2004; Morgan; Rutherford, 1998). Ainda, tem sido apontado que, entre os economistas da época, Veblen seria uma figura aceita e reconhecida, capaz de publicar nas mais importantes revistas científicas da época, colocando-se no centro do debate econômico nas três primeiras décadas do século XX (Cavalieri, 2015). Assim, parece mais provável que a crescente rejeição à pessoa e ao pensamento de Veblen esteja relacionada à acidez mordaz de sua crítica às bases da sociedade norte-americana e ao capitalismo monopolista emergente. ${ }^{22}$

Por outro lado, o cotejamento multidisciplinar da obra de Veblen tem provocado a aproximação contemporânea de autores da Antropologia à abordagem institucionalista, especialmente para os estudos que envolvem a compreensão de instituições econômicas, ao mesmo tempo que agrega economistas heterodoxos, e também aqueles que não são nem economistas e nem antropólogos, mas dispostos ao diálogo interdisciplinar.

\section{Tecendo relações, comparações e considerações finais}

Ao escrever este texto, realizei uma leitura conjunta de obras conhecidas de Veblen e dos antropólogos evolucionistas L. Morgan, E. Tylor e J. Frazer e também do culturalista F. Boas, em busca de elementos de aproximação e de distinção entre as abordagens dos autores. O objetivo foi compreender, a partir do retorno aos clássicos, a forma e alguns dos motivos pelos quais a obra de Veblen tem aparecido no cenário de debates atual, se mostrando uma interface entre Antropologia e Economia. Veblen funda o Institucionalismo Americano valendo-se, entre outras fontes, dos avanços metodológicos e interpretativos desses antropólogos analisados e, ao mesmo tempo, da obra de economistas. Essa característica multidisciplinar tem colaborado para que suas ideias sejam novamente discutidas.

Com relação à comparação das obras, há algumas semelhanças e diferenças que precisam ser exploradas, podendo-se começar pelas afinidades em termos de linguagem e de alguns conceitos. $O$ conceito de "sobrevivências" é comum a todos os autores. A diferença é que Veblen se inte-

22 Todo o parágrafo acima e as citações, com pequenas modificações, foram retirados do parecer anônimo recebido durante o processo de avaliação do artigo junto à revista Nova Economia. 
ressava por identificar as sobrevivências constantes nos comportamentos das classes "superiores", enquanto os antropólogos buscavam nas "massas". Outras questões comuns debatidas foram: a das diferenças culturais; o próprio conceito de cultura; a crítica ao economicismo; o debate sobre a ascendência da humanidade (e a elaboração de esquemas, mesmo que distintos); o que são as instituições, e entre elas a da propriedade privada; o papel dos hábitos na constituição dos comportamentos; os rituais e cerimonialismos, entre outros que foram temas comuns aos autores. Há também muitas semelhanças em termos de métodos, já que predominou a etnologia comparativa. De maneira geral, pode-se argumentar que essas semelhanças resultam tanto da leitura que Veblen fez dos textos desses antropólogos quanto do ambiente acadêmico da época, onde questões similares eram debatidas. Porém, o mais importante é que Veblen se aproximou muito, desde a Economia, da vertente cultural, e isso tem feito toda a diferença para a releitura atual da sua obra.

Também as diferenças são marcantes. As principais que quero destacar são: Veblen não priorizou o estudo das sociedades "primitivas", embora tenha feito inúmeros trabalhos resumindo dados etnográficos e arqueológicos dessas sociedades. No entanto, ele usava dados sobre as "sociedades primitivas" com o interesse de analisar as instituições nas sociedades industriais, o que não era trabalho de antropólogo na época. Veblen se diferenciou também por não aceitar a ideia de civilização como progresso e, por isso, seu esquema de evolução era díspar do convencional entre os antropólogos apresentados. Como consequência dessa forma de conceber a evolução, a noção de cultura era distinta, sendo entendida como funcional às estratégias de dominação. Os antropólogos, de sua parte, também tentavam a desconstrução das ideologias de dominação, mas mostrando que todos tinham cultura.

Outra diferença é que Veblen ficou preso à noção de instintos, sendo que essa foi rechaçada ao longo do século XX ao mesmo tempo que seu esquema evolucionário também era abandonado, enquanto os antropólogos mudavam de direção. No mais, Veblen não realizou aquilo que passou a ser considerado como o divisor de águas na Antropologia: o trabalho de campo. O que Veblen fez, como ele mesmo diz, foi empregar dados "tirados da vida diária, mediante observação direta" da sua própria sociedade (Veblen, 1965 [1988], p. 9), o que não era bem visto e nem aceito na Antropologia e nem na Economia à época. Do lado da Antropologia, as pesqui- 
sas culturalistas de F. Boas redirecionaram a disciplina. Do lado da Economia, após a morte de Veblen veio a crise de 1929, tendo os pressupostos keneysianos conduzido os rumos das discussões por outro caminho.

Independentemente dos rumos tomados, o que se sabe é que os recentes encaminhamentos tanto da Antropologia Econômica quanto dos diferentes ramos institucionalistas do lado da Economia mostram que a discussão sobre as instituições se encontra florescente e que a obra de Veblen está influenciando muito o debate. A questão da origem e como as instituições operam nos processos de mudança, que foi parcialmente abandonada na Antropologia após o prevalecimento do culturalismo boasiano (Deliège, 2013), tem passado por atualização. Consoante a isso, enquanto Veblen tornou-se célebre pelas críticas ao capitalismo e pela demonstração do consumo conspícuo da classe ociosa, as leituras atuais têm ampliado os horizontes.

O fato de Veblen ter demonstrado que as relações do consumo são como textos de um repertório essencial da cultura moderna, que podem ser vistos como códigos por meio dos quais são dados sentidos a um conjunto muito grande de representações e práticas (Rocha; Barros, 2006), tem rendido muitos estudos que extrapolam os limites do consumo de luxo. Sua obra tem agenciado trabalhos de cunho etnográficos em diversos temas como: o consumo de produtos eletrônicos em classes populares (Pinto, 2013); consumo de roupas de brechó (Bittencourt, 2013); dimensões culturais do marketing (Rocha; Barros, 2006) e teorias antropológicas do comportamento do consumidor (Silva-Oliveira, 2010); turismo alternativo (Leal, 2011); explicações para o ethos de classes emergentes (Oliveira-Lima, 2007), e abordagens psicológicas do comportamento do consumidor (ALMEIDA, 2016). Além dessas, muitas pesquisas aplicadas publicadas recentemente no Brasil utilizam a abordagem vebleniana que, de maneira geral, revelam a potência de seu legado ao entendimento de dimensões contemporâneas das relações sociais tangenciadas pelos fluxos de símbolos e objetos dentro e fora de mercados, bem como estudos sobre desenvolvimento e crescimento econômico (Conceição, 2002).

\section{Referências}

ADORNO, T. W. El ataque de Veblen a la cultura. In: ADORNO, T. Crítica de la cultura y sociedad I [1977]. Madrid: Ediciones Akal, 2008. 
ALMEIDA, F. Society and brain: A complementary approach to Thorstein Veblen's conspicuous consumer based on Tibor Scitovsky's neuropsychology. Nova Economia, v. 26, n. 2, 2016.

ARON, R. Avez-vous lu Veblen? Paris: Gallimard, 1970.

BARFIELD, T. The dictionary of anthropology. Malden: Blackwell Oxford, 1997.

BENNETT, J. W. Classic anthropology: Critical essays, 1944-1996. New Jersey: Transaction Publishers, 1998.

BITTENCOURT, V. L. O consumo de roupas de Brechó: um olhar antropológico. Trabalho de Conclusão de Curso (Ciências Sociais). Porto Alegre: UFRGS, 2013.

BOAS, F. Os objetivos da pesquisa antropológica [1932]. In: CASTRO, C. Antropologia culturall Franz Boas. Rio de Janeiro: Jorge Zahar, 2004.

BOAS, F. Os métodos da etnologia [1920]. In: CASTRO, C. Antropologia cultural/Franz Boas. Rio de Janeiro: Jorge Zahar, 2004.

BONTE, P.; IZARD, M. Dictionnaire de l'ethnologie et de l'anthropologie. [S.I.]: Paris: PUF, 1991.

CASTRO, C. Evolucionismo cultural. Rio de Janeiro: Zahar, 2005.

CAVALIERI, M. A. R. Thorstein Veblen entre seus pares economistas: um estudo sobre a audiência e a estrutura argumentativa de sua crítica sistemática ao pensamento econômico. Nova Economia, v. 25, n. 1, 2015.

COLANDER, D.; LANDRETH, H. Pluralism, Formalism and American Economics. Middlebury College Economics Discussion Paper. Middlebury, Vermont. 2004.

CONCEIÇÃO, O. Instituições, crescimento e mudança na ótica institucionalista. (Teses FEE), Porto Alegre: FEE, 2002.

CRUZ, M. Thorstein Veblen: o teórico da Economia Moderna, Teoria Econômica, Psique e Estética da Ordem Patriarcal. [S.1.]: E-book, 2014.

DELIÈGE, R. Une histoire de l'anthropologie: écoles, auteurs et théories. Paris: Éditions du Seuil, 2013.

DOUGLAS, M.; ISHERWOOD, B. Pour une anthropologie de la consommation: le monde des biens [1979]. Paris: Éditions du Regard, 2008.

DUARTE, A. A Antropologia e o estudo do consumo: revisão crítica das suas relações e possibilidades. Etnográfica. Revista do Centro em Rede de Investigação em Antropologia, n. 2. v. 14, p. 363-393, 1 jun. 2010.

DUROUX, P. É. Dictionnaire des anthropologistes. Paris: Éditions Universitaires, v. 10, 1975.

DUVIGNAUD, J. Le langage perdu: essai sur la différence antrhopologique. Paris: PUF, 1973.

EDGELL, S. Veblen: social theorist and social critic a guide to original and secondary sources. Salford: University of Salford, 1987.

ERICKSON, P. A.; MURPHY, L. D. Readings for a history of Anthropological Theory. [S.1.]: University of Toronto Press, 2001.

FABIETTI, U.; REMOTTI, F. Dizionario di Antropologia: etnologia, Antropologia culturale, Antropologia sociale. Bologna: Zanichelli, 2003.

GAGNON, M.-A.; FAILLE, D. La sociologie économique de Thorstein Veblen; pertinences et 
impertinences d'une pensée à contre-courant. Revue Interventions Économiques, n. 36, 2007.

GHIRALDELLI-JUNIOR, P. O destino dos impulsos e o programa social da modernidade. São Paulo em perspectiva, v. 8, n. 2, 1994.

GISLAIN, J.-J.; STEINER, P. La sociologie économique: 1890-1920 Émile Durkheim, Vilfredo Pareto, Joseph Schumpeter, François Simiand, Thorstein Veblen et Max Weber. Paris: PUF, 1995.

HOBSON, J. A. Veblen [1936]. Fairfield: A. M. Kelley, 1991.

HODGSON, G. M. Thorstein Veblen and post-Darwinian economics. Cambridge Journal of Economics, v. 16, p. 285-301, 1992.

HODGSON, G. M. On the evolution of Thorstein Veblen's evolutionary economics. Cambridge Journal of Economics, v. 22, n. 4, p. 415-431, 1998.

KNOEDLER, J. T.; PRASCH, R. E.; CHAMPLIN, D. P. Thorstein Veblen and the Revival of Free Market Capitalism. [S.1.]: Edward Elgar Publishing, 2007.

LARAIA, R. DE B. Cultura: um conceito antropológico [1986]. 12. ed. Rio de Janeiro: Jorge Zahar, 1999.

LEAL, R. E. da S. Minha agência é a sua casa!: uma etnografia do sistema alternativo de viagens e turismo da Região Metropolitana do Recife. Tese (Doutorado em Antropologia) Universidade Federal de Pernambuco, Recife, 2011.

MACHADO, N. Karl Polanyi e o "Grande Debate" entre substantivistas e formalistas na Antropologia Econômica. Economia e Sociedade, v. 21, n. 1, p. 165-195, 2012.

MORGAN, L. H. A sociedade antiga. Ou investigações sobre as linhas do progresso humano desde a selvageria, através da barbárie, até a civilização [1877]. In: CASTRO, C. Evolucionismo cultural. Rio de Janeiro: Zahar, 2005.

MORGAN, M. S.; RUTHERFORD, M. American economics: The character of the transformation. History of Political Economy, [S. 1.], v. 30, n. Suppl. 1, p. 24-26, 1998.

MORRIS, M. Concise dictionary of social and cultural Anthropology. Malden: Blackwell Oxford, 2012.

OLIVEIRA-LIMA, D. N. Ethos "emergente": as pessoas, as palavras e as coisas. Horizontes Antropológicos, v. 13, n. 28, p. 175-202, 2007.

PELTO, J. P. Iniciação ao estudo da Antropologia. Rio de Janeiro: Jorge Zahar, 1967.

PINTO, M. DE R. O consumo de eletrônicos em um grupo de baixa renda: relatos de uma etnografia. Revista de Administração da UFSM, v. 6, n. 3, p. 527-545, 2013.

ROCHA, A. Da; ROCHA, E. P. G. Paradigma interpretativo nos estudos de consumo: retrospectiva, reflexões e uma agenda de pesquisas para o Brasil. Revista de Administração de Empresas, v. 47, n. 1, 2007.

ROCHA, E. O que é etnocentrismo. 8. ed. São Paulo: Brasiliense, 1991.

ROCHA, E.; BARROS, C. Dimensões culturais do marketing: teoria antropológica, etnografia e comportamento do consumidor. Revista de Administração de Empresas, v. 46, n. 4, p. 1-12, 2006.

ROSS, D. The origins of American Social Science. Cambridge: Cambridge University Press, 1991. 
SAHLINS, M. D. Stone age economics. [S.1.]: Aldine Atherton, 1972.

SAHLINS, M. D. Au coeur des sociétés: raison utilitaire et raison culturelle. Paris: Gallimard, 1991.

SAHLINS, M. D.; SERVICE, E. R. Evolution and culture. Ann Arbor: University of Michigan, 1960.

SILVA, V. L. da. Arqueologia da sociologia econômica: a contribuição de Thorstein Veblen. Estudos de Sociologia, v. 13, n. 25, 2008.

SILVA, V. L. da. Fundamentos do institucionalismo na teoria social de Thorstein Veblen. Politica \& Sociedade, v. 9, n. 17, p. 289-323, 2010.

SILVA-OLIVEIRA, J. O olhar antropológico do Marketing: Contribuições da Antropologia do Consumo ao entendimento do Sistema de Produção de Bens e do Comportamento do Consumidor. Revista ADM. MADE, v. 14, n. 2, p. 21-35, 2010.

STANFIELD, J. R. The scope, method, and significance of original institutional economics. Journal of Economic Issues, v. 33, n. 2, p. 230, 1999.

TILMAN, R. Thorstein Veblen and his critics, 1891-1963: conservative, liberal, and radical perspectives. Princeton: Princeton University Press, 1992.

TYLOR, E. B. A ciência da cultura [1871]. In: CASTRO, C. Evolucionismo cultural. Rio de Janeiro: Zahar, 2005.

VEBLEN, T. The place of science in modern civilization and other essays [1919]. New York: Huebsch, 1919.

VEBLEN, T. Teoria da classe ociosa: um estudo econômico das instituições [1899]. São Paulo: Livraria Pioneira Editora, 1965.

VEBLEN, T. Théorie de la classe de loisir. Paris: Gallimard, 1970.

\section{Sobre o autor}

Livio Sergio Dias Claudino-liviosergio@ufpa.br

Universidade Federal do Pará, Abaetetuba, Pará, Brasil.

ORCID: https://orcid.org/0000-0002-1261-1533.

O presente trabalho foi realizado com apoio da Coordenação de Aperfeiçoamento de Pessoal de Nível Superior - Brasil (CAPES), Código de Financiamento 001. Agradeço aos integrantes do Grupo GEMAV: Chaiane Agne, Jonattan Castelli e Rafaela Vendruscolo; a Tiago Lemões; aos professores Octávio Conceição e Paulo Waquil (UFRGS); ao(s) revisor(es) anônimo(s) pelos comentários.

\section{Sobre o artigo}

Recebido em 01 de dezembro de 2019. Aprovado em 17 de fevereiro de 2020. 